\title{
STRUKTUR SEMIOTIK CERITA KEN AROK KARYA TJAHYANINGTYAS DAN ZHAENAL FANANI TEORI TODOROV
}

\author{
Martutik \\ SMPN2 Sumberrejo \\ Hp 081330471856
}

\begin{abstract}
Abstrak : Penelitian dengan judul Struktur Semiotik Cerita Ken Arok Karya Tjahyaningtyas dan Zhaenal Fanani, Teori Todorov.Novel "Ken Aok ken dedes karya tjahyaningtyas dan Ken arok sumelang Gandring Karya Zhaenal Fanani" ini bertujuan untuk menganalisis struktur semiotik. Penelitian ini merupakan penelitian Pendekatan Obyektif dalam metode struktural semiotik.. Sumber data ini adalah Roman ken arok ken dedes karya Tjahyaningtyas dan ken Arok Sumelang Gandring karya Zhaenal Fanani. Penelitian difokuskan pada permasalahan yang berkaitan struktur dan semantiknya.dalam kajian ini akan dianalisis dengan tiga aspek, yaitu aspek semantik, aspek sintaksis, dan aspek verbal. Hasil penelitian sebagai berikut.Pertama, Aspek Sintaksis yang yang menganalisis terdiri dari urutan Spasial, urutan logis, dan urutan kronologis.Kedua,Aspek Semantik yang menganalisis yaitu hubungan sintakmatik (in presentia) dan hubungan paradigmatik (in absentia). Ketiga, Aspek verbal yang menganalisis hal yang berkenan dengan empat kategori, yaitu kategori modus dan kala, kategori sudut pandang, kategori pencerita, dan kategori ragam bahasa.
\end{abstract}

Kata kunci : Sintaksis, Semantik,Verbal

\begin{abstract}
The tittle of this reserch is "Struktur Semiotik cerita Ken Arok karya Tjahyaningtyas and Zhaenal Fanani, Todorov Teori." Novel Ken Arok Ken Dedes made of Tjahyaningtyas, and Ken Arok Sumelang Gandring made of Zhaenal Fanani. "Have the goal, this goal is to analiyse semiotic struktur. This reserch is the objective semiotic struktur methode. The source of the data is ken arok ken dedes made of Tjahyaningtyas and ken arok sumelang gandring made of zhaenal Fanani. The focuse of the resech in the problem related to the structure ang semantic. In this written will be analysed by 3 aspec, thera are: sematic aspec, sintacsis aspec, and verbal aspec. The result of the research are : First, sintacsis aspep analyse, consist of coherence of part of thd data, logic coherence, and cronologic coherence, second semantic aspec analyse relationship beetween semantic (in presense) and relationship paradigmatic (in absense), Therd verbal aspect, analyse someting related to the 4 categories, They are : Modus and time categories, knowledge categories, teller categories and, kinds of the language categories.
\end{abstract}

Keywords : Sintacsise, Semantic, Verbal. 


\section{PENDAHULUAN}

Sebuah karya sastra merupakan bagian dari kesenian yang menggunakan bahasa sebagai proses imaginatif dan selalu berada dalam peradaban kebudayaan manusia. Karya-karya sastra merupakan sebuah sarana untuk menyampaikan ide-ide atau gagasan yang berisi tentang nilai-nilai moral, sosial kemasyarakatan, adat istiadat, dan kritik sosial. Dengan adanya karya sastra tersebut manusia akan lebih bijak dalam memahami pesan moral yang didapatkannya dalam suatu karya sastra atau sebuah cerita.

Dan salah satu karya sastra yang menjadi kajian dalam analisis ini adalah cerita Ken Arok, yang menyimpan potensi multitafsir. Bisa menyisipkan perihal keris bernama sumelang gandring buah karya Empu Sutapasana, tetapi bisa juga eksplorasi jiwa Mpu Gandring yang waswas,sumelang terhadap perilaku Ken Arok. Ini tentu menarik. Lebih-lebih penulisnya, Tjahyaningtyas dan Zhaenal fanani, sudah mengangkat Ken Arok: cinta dan Tahta (2013). Keduanya akan memperkaya ruang imajinasi kita yang sebelumnyansudah diisi informasi perihal kediri dan Singosari dati persektif sejarah.

Tjahyaningtyas dan Zhaenal Fanani sebagai pengarang berusaha untuk memetik unsur-unsur yang lebih otentik dari tawaran tafsir penulisnya atas realitas kontemporer terkait persoalan eksternal sosial politik ataupuninternal psikologis tokoh-tokohnya yang barangkali tidak jauh berbeda dengan realitas hidup psikososial kita saat ini. Tjahyaningtyas dan Zhaenal Fanani menggunakan bahasa Indonesia dalam bukunya. Hal ini bertujuan agar semakin banyak kalangan yang mampu memahami cerita.

Dalam analisis Cerita Ken Arok, Karya Tjahyaningtyas dan Zhaenal Fanani ini, pengarang menggunakan kajian struktural semiotik model Todorov yang akan mengkaji struktur beserta semantiknya. Dalam kajian ini akan dianalisis dengan tiga aspek, yaitu aspek sintaksis, aspek verbal, dan aspek semantik.

Tujuan yang hendak dicapai dalam penelitian ini adalah untuk mengungkap aspek sintaksis, semantik dan aspek verbal dalam Cerita Ken Arok, Karya Tjahyaningtyas dan Zhaenal Fanani berdasarkan strukturalisme semiotik Todorov.

\section{METODE PENELITIAN}

Dalam penelitian ini pendekatan penelitian yang digunakan adalah pendekatan objektif dalam metode struktural semiotik.

Metode struktural semiotik adalah metode gabungan antara metode struktural dan metode semiotik.Metode struktural semiotik bertujuan memaparkan secermat mungkin fungsi dan keterkaitan antar berbagai unsur karya sastra dan tanda bahasa secara bersama-sama menghasilkan sebuah makna yang utuh.

Analisis karya sastra ini menggunakan teori strukturalisme semiotik model Todorov yang memuat aspek-aspek yaitu aspek sintaksis, semantik, dan aspek verbal. Teori ini dipilih karena dapat digunakan untuk mengkaji dengan lengkap unsur-unsur dalam karya sastra, sehingga isi dan maksud dalam cerita Ken Arok, dapat diketahui lebih mendalam.

Teknik pengumpulan data yang digunakan dalam analisis ini adalah teknik studi pustaka

\section{HASIL PENELITIAN \\ Analisis Aspek Sintaksis}

Wacana sastra merupakan sebuah teks naratif yang terdiri atas rangkaian peristiwa. Rangkaian peristiwa tersebut memiliki hubungan kausalitas dan hubungan kronologis. Dalam teks naratif 
Ken Arok,karya Tjahyaningtyas dan Zhaenal fanani ini, akan dianalisis urutan tekstual, urutan logis, dan urutan kronologisnya.

\section{Urutan tekstual}

Urutan tekstual dalam Ken Arok, karya Tjahyaningtyas dan zhaenal fanani dapat dijelaskan ke dalam bentuk sekuensekuen sebagai berikut:

S-1 Ken Endok menikah dengan Gajah Para, seorang pemuda telat kawin.

1.1 Ken Endok belum nenunjukkan tanda-tanda kehamilan padahal sudah berumah tangga selama dua tahun dengan Gajah Para

S-2 Ken Endok dihadang oleh dua lelaki di Tegal Lelateng ketika akan mengirim makanan untuk Gajah Para di sawah.

2.1 Ken Endok bertengkar mulut dengan kedua lelaki yang tak dikenalnya.

2.2 Ken Endok hampir diperkosa oleh kedua lelaki tersebut.

S-3 Seorang lelaki yang mengaku sebagai Dewa Brahma (Tunggul Ametung) datang dan menyelamatkan Ken Endok dari kedua lelaki yang berusaha memperkosanya.

3.1 Ken Endok terpesona dengan lelaki yang mengaku sebagai Dewa Brahma karena dia sangat hebat dan memiliki harta banyak.

S-4 Ken Endok dibawa oleh Tunggul Ametung ke sebuah gubuk dan mendapati dirinya telah terjamah.

S-5 Ken Endok mendapati dirinya hamil muda.

5.1 Ken Endok bingung akan ayah kandung dari anak yang sedang dikandungnya.
S-6 Ken Endok bertemu kembali dengan lelaki yang mengaku sebagai Dewa Brahma.

6.1 Ken Endok diberitahu oleh lelaki tersebut jika kelak anaknya akan menjadi seorang raja.

S-7 Gajah Para dibunuh oleh orang yang tidak dikenal.

7.1 Gajah Para meminta Ken Endok untuk melayaninya, tetapi Ken Endok menolaknya.

7.2 Seseorang datang secara tiba-tiba dan menghantam tubuh Gajah Para hingga meregang nyawa.

S-8 Ken Endok melahirkan seorang anak laki-laki.

S-9 Ken Endok meninggalkan bayinya di sebuah makam.

S-10 Bayi Ken Endok ditemukan oleh seorang gembong pencuri bernama Lembong.

S-11 Ken Endok mendatangi Lembong untuk mengakui bahwa bayi yang ditemukan oleh Lembong adalah anak kandungnya.

11.1 Ken Endok tetap menyerahkan anak tersebut kepada Lembong.

11.2 Bayi tersebut diberi nama Ken Arok.

S-12 Ken Arok tumbuh menjadi anak yang nakal dan suka berjudi.

12.1 Ken Arok menghabiskan harta kekayaan Lembong untuk berjudi.

12.1.1 Ken Arok menjual kerbau yang dititipkan kepala desa kepadanya dan Lembong yang mengganti kerugiannya.

12.2 Ken Arok diusir oleh Lembong karena Lembong kesal dengan semua tingkah laku Ken Arok.

S-13 Ken Arok bertemu dengan Bango Samparan, seorang penjudi dari desa Karuman di tengah jalan.

13.1 Ken Arok diajak oleh Bango Samparan ke tempat perjudian. 


\section{Urutan Logis}

Urutan logis dari sekuen-sekuen pembentuk cerita Ken Arok, Pendiri Dinasti Singasari adalah sebagai berikut: Peristiwa S-2 (Ken Endok dihadang oleh dua lelaki di Tegal Lelateng ketika akan mengirim makanan untuk Gajah Para di sawah.) menyebabkan terjadinya peristiwa pada sekuen S-3 (Seorang lelaki yang mengaku sebagai Dewa Brahma (Tunggul Ametung) datang dan menyelamatkan Ken Endok dari kedua lelaki yang berusaha memperkosanya.) sampai dengan33. Peristiwa S-86 (Rangga Wuni menduduki tahta kerajaan Tumapel dan mendapat gelar Wisnuwardana) menyebabkan S-87 (Rangga Wuni berhasil memimpin Tumapel menjadi tenteram dan aman, serta mengubah nama Tumapel menjadi Singasari.)

\section{Urutan Kronologis}

Urutan kronologis dalam cerita Ken Arok, Pendiri Dinasti Singasari adalah sebagai berikut:

Peristiwa S-1 Ken Endok menikah dengan Gajah Para, seorang pemuda telat kawin.sampai dengan 87. Peristiwa S-87 Rangga Wuni berhasil memimpin Tumapel menjadi tenteram dan aman, serta mengubah nama Tumapel menjadi Singasari.

\section{Analisis Aspek Semantik}

Analisis aspek semantik menghasilkan makna dalam teks. Analisis aspek semantik dalam cerita Ken Arok,karya tjahyaningtyas dan zhaenal fananiterdiri dari hubungan sintagmatik (in praesentia) dan hubungan paradigmatik (in absentia). In praesentia merupakan unsur-unsur yang hadir dalam teks, sedangkan in absentia merupakan unsur-unsur yang takhadir dalam teks. Berikut analisis tentang aspek semantik yang terdapat dalam Ken Arok,

\section{Hubungan In Presentia (Hubungan Sintagmatik)}

Hubungan in presentia atau disebut dengan hubungan sintakmatik merupakan hubungan antar unsur-unsur yang hadir bersama dalam teks cerita untuk digunakan untuk menelaah struktur sastra dengan menekankan pada urutan satuansatuan makna karya sastra yang dianalisis. Dalam anlisis hubungan sintakmatik cerita Ken Arok, ini akan diuraikan tentang tokoh, penokohan, yang kemudian dilanjutkan dengan latar belakang tokoh.

\section{Ken Arok}

Watak dan latar belakang Ken Arok dapat digambarkan pada kutipan berikut ini. Dari kutipan tersebut tergambar jelas akan watak Ken Arok yang tumbuh menjadi seorang laki-laki yang sangat nakal, pembuat kerusuhan, suka merampok, suka berjudi, pemerkosa, bahkan menjadi seorang pembunuh.

\section{Empu Gandring}

Empu Gandring adalah seorang empu yang sangat terkenal akan kemahirannya membuat keris. Empu Gandring memiliki sifat yang tidak tetap akan pendiriannya. Ketika Ken Arok memintanya untuk memperlihatkan keris yang belum selesai dibuat, Empu Gandring mau menurutinya. Padahal, sebenarnya ia tidak mau memperlihatkan keris buatannya sebelum selesai dikerjakan. Pada akhirnya, Empu Gandring tewas ditusuk menggunakan keris tersebut olah Ken Arok.

\section{Ken Dedes}

Ken Dedes adalah istri Tunggul Ametung yang berasal dari Desa Panawijen.Ken Dedes terkenal sebagai wanita yang sangat cantik.Pada kisahnya, Ken Dedes memiliki sikap yang tenang dan kurang berani dalam mengungkap kebenaran.Hal tersbut tergambar pada sikap Ken Dedes yang tidak mau mengatakan kejadian yang sebenarnya tentang kejadian tewasnya Tunggul 
Ametung.Ken Dedes diselimuti dengan rasa takut yang begitu besar karena ancaman Ken Arok.Ia tidak mengatakan fakta yang sebenarnya bahwa pelaku pembunuhan terhadap Tunggul Ametung adalah Ken Arok.

\section{Hubungan In Absentia (Hubungan Paradigmatik)}

Hubungan in absentia atau hubungan paradigmatik merupakan hubungan antara unsur-unsur yang tidak hadir dalam sebuah teks. Hubunganhubungan unsur-unsur pendukung tersebut akan membantu dalam memperjelas maksud suatu teks. Unsurunsur tersebut menjelaskan tentang sifatsifat pelaku, identitas, perasaan, suasana, dan filosofi atau disebut juga dengan indeks.Sedangkan unsur pendukung yang menjelaskan tentang waktu disebut dengan informan.

\section{Indeks}

Indeks adalah satuan-satuan yang menerangkan sifat tokoh, identitas, perasaan, suasana, psikologi, dan lain sebagainya. Dalam cerita Ken Arok, ini akan dibahas mengenai suasana.

\section{Suasana kekaguman}

Perasaan kagum dirasakan oleh orang-orang yeng mengetahui dan melihat kelincahan, kecerdikan, serta kenekadan Ken Arok. Dengan lincahnya Ken Arok melompat dengan cepatnya ketika is dikejar oleh penduduk Taloka yang sebenarnya sudah dipenuhi rasa jengkel kepadanya.

\section{Suasana Aneh}

Suasana aneh banyak dialami oleh para tokoh dalam cerita. Suasana aneh ini sebagian diawali dengan rasa kagum maupun heran akan suatu peristiwa. Misalnya, suasana aneh dialami oleh Ken arok ketika menemukan logam yang memancarkan sinar.

\section{Analisi Aspek Verbal}

Analisis aspek verbal terhadap novel Ken Arok, memusatkan pada bagaimana teks dianalisis berdasarkan presepsi yang diinginka. Aspek verbal mengacu pada bentuk kategori-kategori yang mendasar pada kehadiran teks tersebut, sehingga kategori-kategori itu terangkum dalam beberapa pokok analaisis yang meliputi empat bagian, yaitu kategori modus dan kala, kategori sudut pandang, kategori pencerita, dan ragam bahasa.

\section{Amanat}

Amanat merupakan peran yang hendak disampaikan oleh pengarang kepada pembaca.Pesan tersebut disampaikan dalam wujud uraian tersirat dan juga secara terirat.Adapun amanat dalam cerita Ken Arok, adalah pesan yang dapat dijadikan peringatan bagi manusia, khususnya bagi para penguasa agar tidak ambisius dalam memperoleh kekuasaan. Ambisi yang besar tanpa memperhatika norma-norma yang berlaku hanya akan menjerumuskan dirinya sendiri dalam sebuah kehancuran. Hal tersebut tergambar pada apa yang dialami oleh Ken Arok, dimana akibat ambisinya dia tewas akibat dendam para pemegang kekuasaan Singasari.

\section{Gaya Bahasa}

Gaya bahasa yang digunakan dalam cerita Ken Arok, adalah gaya langsung dan gaya tidak langsung.

Gaya Langsung

Gaya bahasa langsung ini digunakan dalam percakapan-percakapan antar tokoh dalam cerita.

Gaya tidak Langsung

Selain, gaya bahasa langsung cerita Ken Arok, juga menggunakan gaya bahasa tidak langsung.

\section{Kategori Sudut Pandang}

Kategori sudut pandang akan membawa pandangan subjektif maupun 
objektif mengenai peristiwa-peristiwa yang diungkapkan pada cerita. Tokohtokoh yang ditampilkam bukan hanya memandang tokoh tersebut tetapi juga dipandang.Dalam cerita Ken Arok, menggunakan kategori pandangan tetap dan pandangan berubah-ubah.Sehingga dapat dikatakan bahwa sudut pandang persona ketiga "Dia maha tahu".Sudut pandang yang digunakan tersebut tergambar pada sebagian besar teks.

\section{Kategori Pencerita}

Pencerita dalam cerita Ken Arok, merupakan pencerita primer, yaitupencerita yang hanya berperan di luar teks.Pencerita hanya sekedar mengemukakan peristiwa-peristiwa yang terangkai dalam sebuah teks cerita tentang perjalanan hidup Ken Arok.Sampai kematian Ken Arok akibat dibunuh oleh Tohjaya, anak tirinya atau anak kandung Anusapati.

\section{Kategori Ragam Bahasa}

Ragam bahasa merupakan variasi bahasa yang digunakan di dalam teks. Dalam cerita Ken Arok,. Dalam cerita Ken Arok.

\section{SIMPULAN}

Analisis cerita Ken Arok, tjahyaningtyas dan zhaenal fanani ini menggunakan teori struktural semotik model Todorov yang meliputi tiga aspek, yaitu aspek sintaksis, aspek semantik dan aspek verbal.

Aspek sintaksis meliputi urutan tekstual, urutan logis, dan urutan kronologis yang menceritakan tentang perjalanan hidup Ken Arok mulai dari kelahirannya hingga meninggal
dunia.Dalam analisis cerita Ken Arok, didapatan 87 sekuen.

Aspek semantik secara keseluruhan dalam teks cerita Ken Arok, meliputi simbol dan makna sinar serta simbol dan makna keris. Selain itu, aspek semantik juga digambarkan dengan adanya hubungan in presentia atau hubungan sintakmatik dan hubungan in absentia atau hubungan paradigmatic.

Sedangkan aspek verbalnya meliputi (1) modus dimana Ken Arok berperan sebagai orang yang menjadi tokoh utama dalam cerita. (2) Kala dalam cerita Ken Arok, menjelaskan jalur waktu dalam cerita fiktif. (3) Sudut pandang dan penceritaan menjelaskan tentang cara pengarang menyajikan suatu tokoh, dimana pengarang menyampaiakn cerita menggunakan sudut pandang keberapa. (4) Ragam bahasa mengetahui ragam bahasa apa yang disampaikan oleh pengarang pada Ken Arok.ken dedes dan ken arok sumelang gandring

\section{DAFTAR PUSTAKA}

Nurgiyantoro, Burhan. 1994. Teori Pengkajian Fiksi. Yogyakarta: Gadjah Mada University Press.

Pradopo, Rachmat Djoko. 1995. Beberapa Teori Sastra, Metode Kritik, dan Penerapannya. Yogyakarta: Pustaka Pelajar.

Todorov, Tzvetan. 1985. Tata Sastra. Jakarta: Djambatan (Terjemahan Okke K. S. Zaimar).

Tjahyaningtyas, 2015. Ken Arok Ken Dedes. Surabaya: Gramatikal

Zhaenal, Fanani. 2014. Ken Arok, Sumelang Gandring. Solo: Metamind. 